\title{
The Must-Have in Robotic Heart Surgery: Haptic Feedback
}

\author{
Eva U. Braun ${ }^{1}$, Hermann Mayer ${ }^{1}{ }^{2}$, Alois Knoll ${ }^{2}$, Ruediger Lange ${ }^{1}$ \\ and Robert Bauernschmitt ${ }^{1}$ \\ Technische Universität München \\ ${ }^{1}$ German Heart Center Munich, Clinic for Cardiovascular Surgery, \\ ${ }^{2}$ Fakultät für Informatik, Robotics and Embedded Systems, Technische Universität München
}

Germany

\section{Introduction}

The minimally invasive endoscopic surgery was introduced in the late 1980s in the abdominal surgery as revolutionary surgical technique (Voges et al., 1997). Surgeons no longer needed to physically place their hands within the body to perform an operation. In minimal invasive surgery, instruments and viewing equipments are inserted into the body through small incisions. Long manipulators are used to perform operations under manual guidance. This does not only minimize the collateral surgical trauma of an access incision but results also in quicker recovery.

In heart surgery the introduction of endoscopic techniques were promising, but not satisfying like the application of robots in other surgical disciplines (Bholat et al., 1999; Gutt et al., 2004; Mitsuishi et al., 2000). Complex cardiac surgery had to be performed by long instruments without tremor filter or adequate freedom of movement, so satisfactory results were missing. In heart surgery pure endoscopic techniques have not established since the demanded high precision in this speciality did not reached with endoscopic instruments only.

The promise of telemanipulated endoscopic assistance was to eliminate many of the beginning impediments, with the concurrent enhancements of motion scaling, tremor filtration, 3-dimensional vision and fulcrum effect. The surgeon could now operate with a surgical mechatronic assist system in a comfortable, dextrous and intuitive manner.

The solution for the initial problems was the implementation of telemanipulators that offer with the endoscopic instruments as much degrees of freedom in movement as the hand of the surgeon in conventional open surgery performing 6 degrees of freedom instead of four in conventional endoscopic instruments. Furthermore the telemanipulator had to dispose of 3D-optic and a filter of tremor (Suematsu \& Del Nido, 2004). The new system has been a telesystem controlled remotely by the surgeon.

\& The implementation of totally endoscopic heart surgery was realised ten years later with the telemanipulator Da Vinci ${ }^{\circledR}$ (Intuitive Surgical, Inc., Sunnyvale, CA, USA) after introducing endoscopic surgery in abdominal surgery.

Nevertheless technical limitations still exist that limit the application in special heart diseases and surgical indications in expert medical centres only. 
This telemanipulated technology is available for a minimal part of heart surgical patients only since the technical inconvenience of the system and the clumsy system is considerably limited in valve surgery, congenital heart surgery and a bigger part of bypass surgery.

The necessity of haptic feedback is discussed controversially by robotically working surgeons and haptic engineers (Bethea et al., 2004; Fager, 2004; Hu et al., 2004). The postulate, that the integration of a supplementary haptic channel in addition to the visual channel improves the quality of surgical work and enhances the immersion for the surgeon in a remote system, is not yet demonstrated and evidenced.

For virtual and artificial scenarios tactile sense and haptic feedback is an essential part (Darggahi \& Najarian, 2004; Van Beers et al., 1999), but in the research of surgical telepresence for remote real scenarios the necessity of haptic feedback is still discussed very intensely. Several microsurgical telerobot systems are implemented by research groups all over the world (Cavusoglu et al., 2003; Garcia-Ruiz et al., 1997; Kwon 1998), but important questions and problems arising while operating are not answered and solved sufficiently. The breaking of surgical suture material and the damage of tissue are basic and unsolved problems in telemanipulated surgery. A further hypothesis is not yet explored: The especially high fatigue of the surgeon while and after robotic operations is caused in visual compensation of the skills and movements (Thompson et al., 1999). The basic solution seems to be the implementation of force feedback.

In our study haptic feedback is built up in the experimental setup of a surgical telemanipulator system (fig. 1) as technical modification (Schirmbeck et al., 2004 a; Bauernschmitt et al., 2005 a; Mayer et al, 2005), the application on surgical skills is analysed and evaluated ( Schirmbeck et al., 2005 ; Bauernschmitt et al., 2005 b; Freyberger et al., 2005; Mayer et al., 2005).

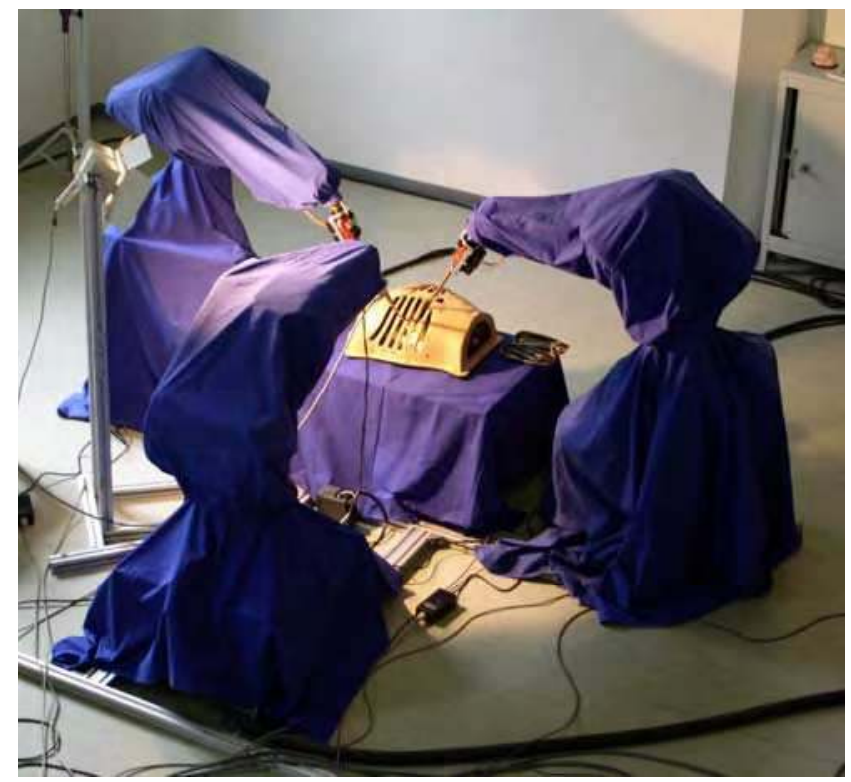

Figure 1. Surgical telemanipulator system: Two instruments and one 3-D camera 


\section{Methods}

\subsection{Robotic system for endoscopic heart surgery}

We built up a telemanipulated surgical experimental platform with commercially available equivalent surgical instruments to present comparable conditions for the surgeons. The difference and advancement is our implementation of haptic feedback in the instruments and the new robotic system.

The setup comprises like typical systems for robotic surgery an operator-side master console for in-output and a patient-side robotic manipulator that directly interacts with the operating environment.

A bi-manual telemanipulator is built up not only capable performing delicate operations, but also capable of applying real-time image processing tools like coronary artery detection (Nagy et al., 2004), navigation features (Mayer et al., 2004) and autonomous procedures (Schirmbeck et al., 2004 b).

\section{Telemanipulator system}

The robotic system consists of two surgical manipulators, which are controlled by two PHANTOM $^{\circledR} 1.5$ input devices (SensAble Technologies, Inc., Woburn, MA, USA), and a third robot, which carries a stereoscopic camera (Richard Wolf $\mathrm{GmbH}$, Knittlingen, Germany). Each manipulator is composed of a KUKA KR 6/2 robot (KUKA Roboter GmbH, Augsburg, Germany), that bears a surgical instrument of Intuitive Surgical ${ }^{\circledR}$. The KUKA robot disposes of six degrees of freedom. The surgical instruments provide three degrees of freedom. Therefore each robotic arm has eight degrees of freedom which enables free surgical manipulation via trocar kinematics. A micro-gripper at the distal end of the shaft can be rotated and the adaptation of pitch and yaw angles is possible.

We developed an adapter to link the robotic arm with the instrument. For security reasons all flange adapters are equipped with magnetic security couplings. Those disengaged exercising forces exceed a certain level and might cause harm on instruments or tissue. All movable parts of the gripper are driven by steel wires. Their motion is controlled by four driving wheels at the proximal end of the instrument, one four each degree of freedom (two for yaw of the fingers). In order to control the instrument, we have flanged servos to each driving wheel by means of an Oldham coupling. This guarantees instrument movement free of jerk. The servo controllers are connected via serial lines to a multiport card. This redundancy renders the end effector possible to reach every position and orientation within the working space under restriction of trocar kinematics for surgical use.

\section{Haptic instruments and haptic interface}

We modified the instruments of the Da Vinci ${ }^{\circledR}$ telemanipulator system for measuring forces while executing surgical tasks (Bowersox et al., 1998). Since the shaft of the surgical instruments is made of carbon fibre, force sensors have to be very sensitive and reliable. Therefore strain gauge sensors are applied, which are employed for industrial force registration. The sensor gauges are applied at the distal end of the instrument's shaft near the gripper in order to display realistic forces during operation.

The strain gauge force sensors measure forces along two translational directions of the instrument's shaft. One full bridge of sensors is used for each direction. Forces are displayed to the user by means of two PHANTOM ${ }^{\circledR}$, which act at the same time as input devices. The signals of the sensors are amplified and transmitted via CAN-bus to a PC system. Since reading of direct sensor is associated with noise a smoothing filter is applied in order to 
stabilize the results. Position and orientation of the manipulators are controlled by the two PHANTOM ${ }^{\circledR}$ input devices.

The working space of approximately $20 \times 25 \times 40 \mathrm{~cm}$ provides enough space to perform surgical procedures. The user controls a stylus pen equipped with a switch that can be used to open and close the micro-grippers. The basic idea of minimally invasive surgery is that only small incisions have to be made into the surface of the patient's body. The translational movements of the instruments are essentially restricted by shifts and rotations about these fulcrums (trocar kinematics).

The most interesting feature of the employed PHANTOM ${ }^{\circledR}$ devices is their capability of displaying forces to the user. Forces are fed back by small servomotors incorporated in the device. They are used to steer the stylus pen in a certain direction. This creates the impression of occurring forces, while the user is holding the pen at a certain posture.

Optical system: 3D-endoscope and head mounted display

To enable proper telemanipulation a 3D-display (Falk et al., 2001) is indispensable providing a distinct vision of the region of interest. An additional robot is equipped with the stereo endoscopic camera.

This camera can also be moved by means of trocar kinematics as the instruments and can be actively controlled either by the operator or automatically track the instruments. Images taken from the stereo camera system can be displayed via three options, while time delay and least asynchrony in video have to be avoided (Thompson et al., 1999). One is a head mounted display (HMD) that is part of the input console. The second possibility is to alternately display left and right images on a Cathode Ray Tube- (CRT-) screen. In this case, the operator has to wear shutter glasses, which are triggered by the output on the screen. A third option is the projection of online-acquired polarized operation sequences on a silver screen with two video projectors. The projectors are equipped with polarising filters that are orthogonally arranged. Observers have to wear glasses with an appropriate polarisation for the corresponding eye.

\subsection{Evaluation of force feedback Human participants}

The human subjects of this study included 25 surgeons divided in three groups within the Clinic for Cardiovascular Surgery in the German Heart Center Munich in different levels of surgical training and age (table 1).

\begin{tabular}{|c|c|c|c|c|}
\hline & $\begin{array}{l}\text { all participants } \\
n=25\end{array}$ & \begin{tabular}{|l}
$\begin{array}{l}\text { young } \\
\text { surgeons } \\
n=8\end{array}$ \\
\end{tabular} & $\begin{array}{l}\text { experienced } \\
\text { surgeons } \\
n=12\end{array}$ & \begin{tabular}{|l} 
robotic \\
surgeons \\
$n=5$
\end{tabular} \\
\hline $\begin{array}{l}\text { Surgical experience } \\
\text { (years) } \\
\text { mean value (sd) }\end{array}$ & $\begin{array}{l}6.1 \\
( \pm 7.4)\end{array}$ & $\begin{array}{l}0.4 \\
( \pm 0.3)\end{array}$ & $\begin{array}{l}11.5 \\
( \pm 7.6)\end{array}$ & $\begin{array}{l}2.4 \\
( \pm 2.0)\end{array}$ \\
\hline $\begin{array}{l}\text { Age (years) } \\
\text { mean value (sd) }\end{array}$ & \begin{tabular}{|l}
36 \\
$( \pm 8)$
\end{tabular} & \begin{tabular}{|l}
29 \\
$( \pm 7)$
\end{tabular} & $\begin{array}{l}39 \\
( \pm 8)\end{array}$ & $\begin{array}{l}39 \\
( \pm 5)\end{array}$ \\
\hline
\end{tabular}

Table 1. Random sample of the human subjects for the evaluation of haptic feedback

One group of robotically working surgeons and two groups of surgeons without experience in robotic surgery (one group with conventionally experienced surgeons and one with young surgeons) were evaluated. 
Every surgeon executed three surgical tasks three times under three different haptic levels (no haptic feedback, 1:1 real haptic feedback and 1:2 doubled force feedback). The order of the haptic conditions (type of task and haptic condition) were completely balanced to avoid learning effect and were double blinded.

\section{Training skills}

Before executing the main surgical tasks of the evaluation, the trainees got 15 minutes to get familiar with handling the robotic system.

First, soft coloured pellets had to be transferred from one cup and in a second next right to the first one. Second, a rubber band had to be threaded through five eyelets. In addition the surgeons got time to tie several knots to be prepared for the main tasks of the evaluation.

\section{The surgical tasks}

The study intended basic surgical and cardiac surgical procedures. Knot tying, breaking suture material and detection of arteriosclerosis had to be performed in a defined cycle with double blinding. These tasks imply at least basic knowledge in surgical principles. The participants dealt with three different levels of haptic feedback: no haptic, actually fed back forces and enhanced force feedback. During the entire experiment, the arising forces were recorded.

Breaking of suture material:

The breaking of suture material represents the amount of telepresence and immersion of the robotic system for the surgeons. The surgeons had to tension the thread until the supposed breaking point and had to mention this point before breaking. The difference of force between the supposed and the real breaking of a surgical thread was measured in Newton. The used surgical suture material Prolene ${ }^{\circledR}$ 6-0 (ETHICON Inc., Somerville, NJ, USA) is a common and frequently used non-absorbable thread made from Polypropylene in heart surgery.

Knot tying:

The human subjects had to tie surgical knots with two surgical instruments equipped with haptic feedback. The surgeons had ten minutes to perform precisely as much knots in alternate way (left and right taught knots) as possible. The total number of knots, the applied forces and the breakage of suture material while knot tying were recorded. The speed and course of motion and the coordination of the graspers were analysed.

In addition the trauma of the surrounding tissue has been rated while knot tying. Following parameters have been analysed: number of dents, holes, fissures and breaks of tissue. Furthermore, the number of outbreaks of knots and insufficient knots were counted.

The finished objects with the knotted tissue were analysed in completion to the rated variables of the video recording.

Detection of arteriosclerosis:

The surgeons had to detect possible stenosis with one haptic instrument in realistic arteries made from polymer precisely and at the same time rapidly.

The errors in detecting short, long or no stenosis in three arteries were counted. The applied forces while detecting were recorded in Newton and the time of detecting in seconds.

The critical flicker fusion frequency CFF

The critical flicker fusion frequency (CFF) is an individual part of the Wiener Testsystem (Schuhfried $\mathrm{GmbH}$, Mödling, Austria) analysing the progression of fatigue during the evaluation (Wiemeyer, 2002). The CFF is regarded as an indicator for the central-nervous 
function capacity, the activation level and the progression of fatigue during practical tasks (Johansson \& Sandström, 2003).

The flicker fusion frequency has been identified between three blocks of tasks with the three different degrees of haptic levels (no haptic, 1:1 haptic and 1:2 haptic feedback).

\section{Results}

\subsection{Surgical knot tying}

Force feedback influences the application of forces significantly $(p<0,05)$ in surgical knot tying. In increasing the force feedback the applied forces are reduced significantly $(p \leq 0,05)$. The experience of the surgeons does not influence the amount of applied forces $(p>0,05)$. Haptic feedback does not show any influence on the quality of surgical knot tying $(p=0,05)$.

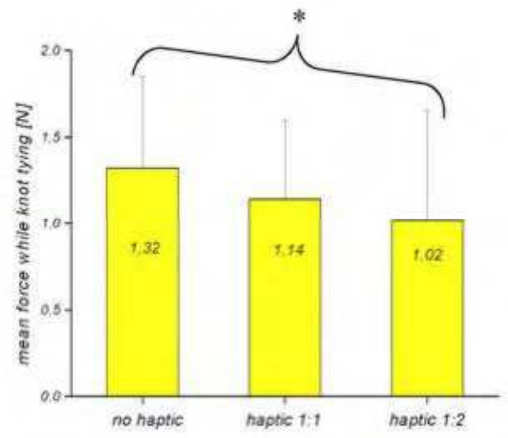

Figure 2. Forces while knot tying. With increasing haptic feedback the applied forces decrease significantly, ${ }^{*} \mathrm{p}<0.05$

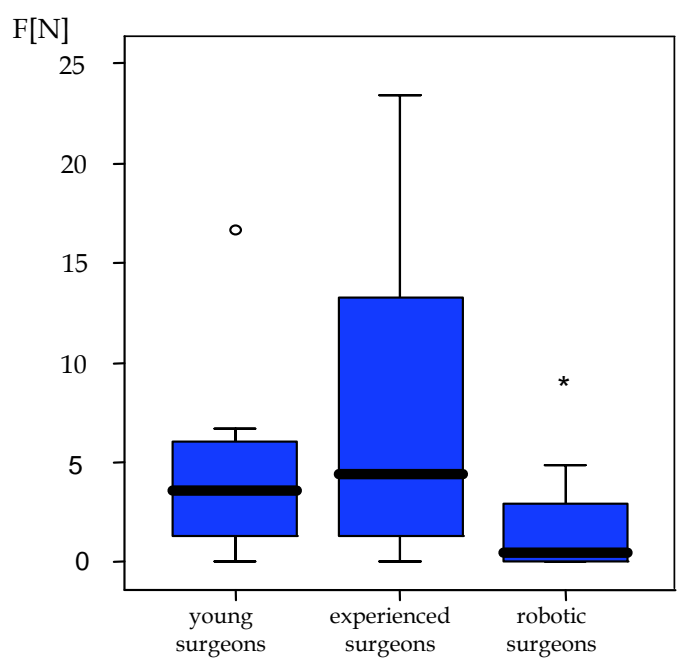

Figure 3. Robotic surgeons apply significantly less forces while knot tying with doubled force feedback, * $p<0,05$ 


\subsection{Breaking of suture material}

The difference of forces was calculated where the thread was breaking supposed by the surgeon and the force where the thread was actually breaking. Haptic feedback showed a significant effect of the force difference $(p<0,05)$. In increasing the haptic feedback the difference decreased $(p<0,05)$, which signifies the precision of the estimated force when the thread was breaking and the high grade of telepresence of the telemanipulator system.

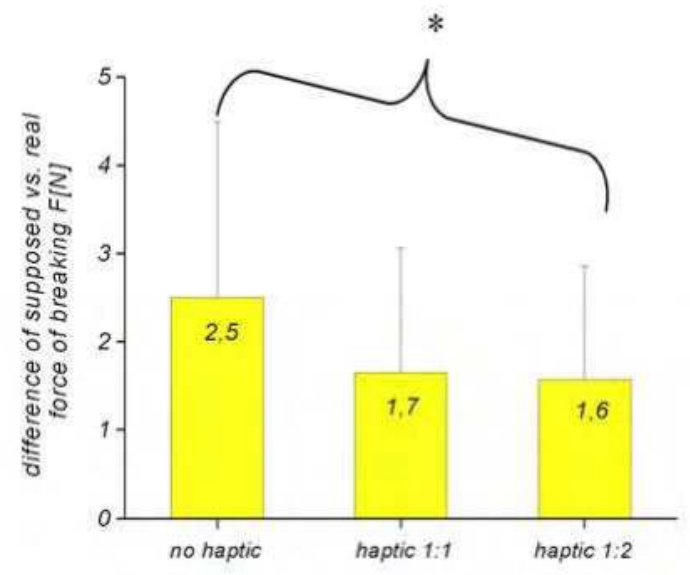

Figure 4. The difference of the supposed and the real force while breaking a surgical suture decreases significantly with haptic feedback, ${ }^{*} p<0.05$

\subsection{Detection of stenosis}

Haptic feedback influences significantly the amount of applied forces while detecting arteriosclerosis $(p<0,05)$. In increasing the force feedback the applied forces decrease significantly $(p<0,05)$. This effect is independent of the surgical experience $(p>0,05)$.

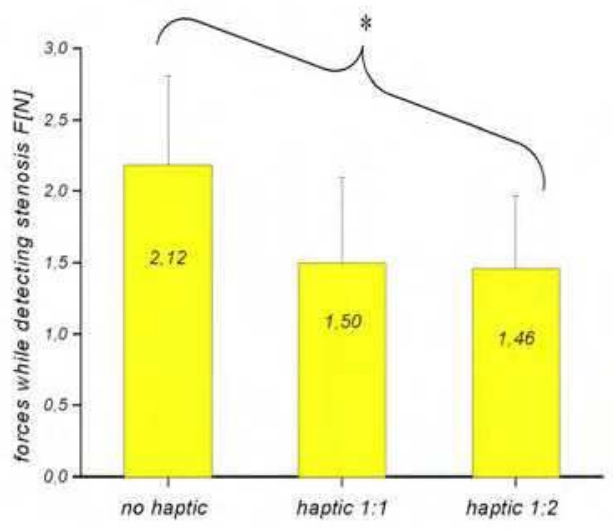

Figure 5. The applied forces decrease significantly $\left({ }^{*} p<0.05\right)$ with the increase of haptic feedback 


\subsection{Fatigue of the surgeons}

The visual fatigue decreases significantly while operating with haptic feedback for young and conventionally experienced surgeons. Haptic feedback decreases the visual stress and fatigue $(\mathrm{p}<0,05)$.

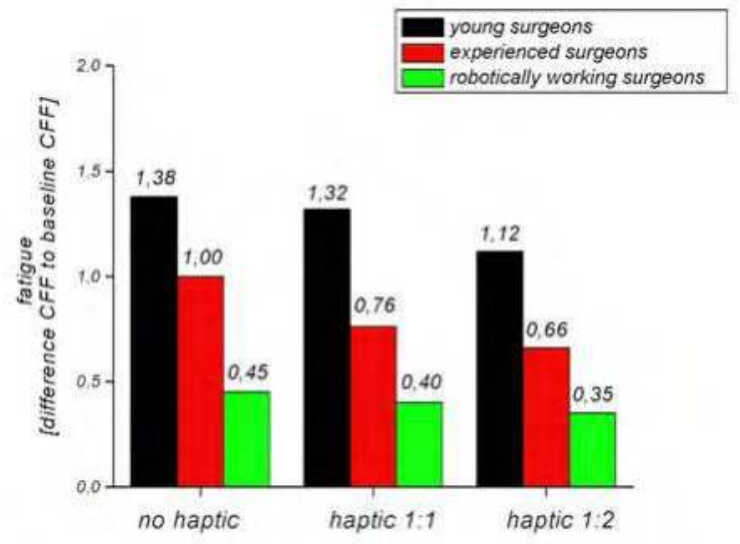

Figure 6. The critical flicker fusion frequency CFF: the visual fatigue decreases with increasing haptic feedback in young, experienced and robotic surgeons

\section{Conclusion}

Robots have a number of advantages over humans in performing routine manipulation tasks. Their accuracy and repeatability allow robots to succeed in the medical and surgical market. Some of the weaknesses in current robotic devices, such as substantial lack of haptic feedback and adaptability are to be highlighted. Currently it is not possible to "program" a robot to perform steps of a surgical operation autonomously. Nevertheless, some of these limitations do not prevent robots from being useful in the operating room; rather considerable human, technical and surgical input, guidance and advancement are needed. Surgical robots can be viewed as "extending and enhancing human capabilities" rather than replacing surgeons, in contrast to the example of industrial replacement of humans by robots.

Intuitive Surgical ${ }^{\circledR}$ intended to create with the Da Vinci ${ }^{\circledR}$ Surgical System a conception of a surgeon-robot interface so transparent to the surgeon that his set of skills can be used in a natural and instinctive manner. Its accurate visualisation is critical since visual cues are used to compensate for the loss of haptic feedback.

The haptic feedback is currently limited to interact with rigid structures, such as tool-on-tool collisions, not soft tissues. This requires the surgeon to rely on visual feedback in tasks such as suturing. Especially for fine suture material approaches began in research groups to analyse haptic feedback (Okamura, 2004; Kitagawa et al., 2005), but the way of the evaluating setup is not fulfilling the special medical interest for heart surgeons. The basic consideration in our work is to offer the heart surgeon an accessory sensory channel in addition to the visual channel not only to avoid breakage of surgical suture material and tissue, but also to decrease visual fatigue. 
New applications of the technology are beginning to emerge as creative surgeons do their work (Marohn \& Hanly, 2004; Maurin et al., 2004). Nevertheless, present-day robotic surgical systems have limitations that have slowed the widespread introduction and the continuation. One major problem is the lack of haptic (Czibik et al, 2002; Awad et al., 2002). A second major concern is the cumbersome and not versatile nature of the robotic system. It is quite easy to envision integrated imaging, navigation and enhanced sensory capabilities being available in the next generation of telesurgical systems (Howe \& Matsuoka, 1999; Kennedy et al., 2002).

The goal of our experiments was to examine claims about necessity of force feedback for robot-assisted surgical procedures in cardiac surgery. We present a novel approach of a robotic system for minimally invasive and endoscopic surgery. The main purposes of the system are evaluation of force feedback and machine learning. The performance of certain surgical tasks like knot tying will profit from this feature. Experiments have shown that haptic feedback can be employed to prevent the surgeon from potentially harmful mistakes. Tension of thread material and tissue parts can be measured and displayed in order to restrict force application to tolerable amplitude. In addition, the collision of instruments can be detected and intercepted by the evaluation of real-time forces. Using multi-dimensional haptic styluses, forces are measured at the surgical instruments and fed back into the surgeon's hands.

In our experimental setup, the feel for different and morbidly changed tissues cannot be analysed sufficiently. The setup of the robots does not allow to suture for example anastomosis of arteries. Leak-proof stitches could be an excellent parameter for surgical quality. In addition, the amelioration of our visual display terminal is necessary.

The next generation of surgical experimental telemanipulator with haptic feedback, semiautonomous capability and navigation tool is arising.

Future plans are the evaluation of real tissue to test the variable surgical quality with haptic feedback and the implementation of the results in this advanced surgical robotic system for the adoption in the operating room.

For the future clinical use the perfection is planned by improving the set-up of the instruments and by incorporating these results of the evaluation into the control software. A simulation environment is designed for modelling haptic interaction with a tissue model. This can be applied for offline evaluation of critical tasks. In our experimental set-up, we are able to demonstrate that the surgical procedure in robotic heart surgery is safer, quicker and gentler for the patient and more comfortable for the surgeon using force feedback.

Consequently, we require haptic feedback for surgical robotics to increase the safety of patients, to increase the ease of handling for the surgeon in a complex surgical environment, to relieve the surgeon's fatigue and to increase the number of indications for surgery and the variety of robotic applications for surgery.

Future surgical systems with integrated haptic feedback could be used to train young surgeons for exercising and teaching critical and difficult steps of surgical operations by the system as simulator.

\section{References}

Awad, H.; Wolf, R.K. \& Gravlee, G.P. (2002). The future of robotic and cardiac surgery. J Cardiothor Vasc An, 2002;16(4):395-6 
Bauernschmitt, R.; Schirmbeck, E.U.; Mayer, H.; Nagy, I.; Knoll, A.; Wessel, N.; Wildhirt, S.M. \& Lange, R. (2005 a). Telemanipulator enhanced heart surgery: implementation of autonomous procedures, Biomed Tech, 2005, 50,1(2):1260-1

Bauernschmitt, R.; Schirmbeck, E.U.; Knoll, A.; Mayer, H.; Nagy, I.; Wessel, N.; Wildhirt, S.M. \& Lange, R. (2005 b). Towards robotic heart surgery: Introduction of autonomous procedures into an experimental surgical telemanipulator system. Int J Med Robot Comput Assisted Surg, 2005,1(3):74-9

Bethea, B.T.; Okamura, A.M.; Kitagawa, M.; Fitton, T.P.; Cattaneo, S.M.; Gott, V.L.; Baumgartner, W.A. \& Yuh, D.D (2004). Application of haptic feedback to robotic surgery. J Laparoendosc Adv Surg Tech, 2004;14(3):191-5

Bholat, O.S.; Haluck, R.S., Murray, W.B.; Gorman, P.J. \& Krummel T.M.(1999). Tactile feedback is present during minimally invasive surgery. J Am Coll Surgeons, 1999;189(4):349-55

Bowersox, J.C.; Cordts, P.R. \& LaPorta, A.J. (1998). Use of an intuitive telemanipulator system for remote trauma surgery: an experimental study. J Am Coll Surg, 1998;186:615-21

Cavusoglu, M.C.; Williams, W.; Tendick, F. \& Sastry, S.S. (2003). Robotics for telesurgery: Second generation Berkeley/UCSF laparoscopic telesurgical workstation and looking towards the future applications. Industrial Robot, Special Issues on Medical Robotics, 2003;30(1):22-29

Czibik, G.; D’Ancona, G.; Donias, H.W. \& Karamanoukian, H.L. (2002). Robotic cardiac surgery: Present and future applications. J Cardiothor Vasc An, 2002;16(4):495-501

Darggahi, J. \& Najarian, S. (2004). Human tactile perception as a standard for artificial tactile sensing - a review. Int J Med Robot Comput Assisted Surg, 2004;1(1):23-35

Fager, P.J. (2004). The use of haptics in medical applications. Int J Med Robot Comput Assisted Surg, 2004;1(1):36-42

Falk, V.; Mintz, D.; Grunenfelder, J.; Fann, J.I. \& Burdon, T.A. (2001). Influence of threedimensional vision on surgical telemanipulator performance. Surg Endosc, 2001;15(11):1282-8

Freyberger, F.K.B.; Popp, M.M.; Färber, B.; Mayer, H. \& Schirmbeck, E.U. (2005). Experimentelle Evaluation haptischer Rückmeldung eines robotergestützten Systems für minimal-invasive Herzchirurgie. Zustandserkennung und Systemgestaltung, Fortschritt-Berichte VDI, 2005, Vol. 19, ISBN 3-18-302222-2

Garcia-Ruiz, A.; Smedira, N.G.; Loop, F.D.; Hahn, J.F.; Miller, J.H.; Steiner, C.P. \& Gagner, M. (1997). Robotic surgical instruments for dexterity enhancement in thoracoscopic coronary artery bypass graft. J Laparoendosc Adv Surg Tech A, 1997;7(5):277-83

Gutt, C.N.; Oniu, T.; Mehrabi, A.; Kashfi, A.; Schemmer, P. \& Büchler, M.W. (2004). Robotassisted abdominal surgery. Brit J Surg, 2004;91(11):1390-7

Howe, R.D. \& Matsuoka, Y. (1999). Robotics for surgery. Annual Review of Biomedical Engineering, 1999;1:211-40

$\mathrm{Hu}$, T.; Tholey, G.; Desai, J.P. \& Castellanos, A.E. (2002). Evaluation of a laparoscopic grasper with force feedback. Surg Endosc,2002;18(5):863-7

Johansson, A. \& Sandström, M. (2003). Sensitivity of the human visual system to amplitude modulated light. Arbetslivsrapport Nr. 2003:4. Arbetslivsinstitutet, National Institute for Working Life 2003. Umeå, Sweden 
Kennedy, C.W.; Hu, T.; Desai, J.P.; Wechsler, A.S. \& Kresh,. JY. (2002). A novel approach to robotic cardiac surgery using haptics and vision. Cardiovascular Engineering, 2002;2(1):15-22

Kitagawa, M.; Dokko, D.; Okamura, A.M. \& Yuh, D.D. (2005). Effect of sensory substitution on suture-manipulation forces for robotic surgical systems. J Thorac Cardiovasc Surg, 2005;129(1):151-8

Kwon, D.-S.; Woo, K.Y.; Song, S.K.; Kim, W.S. \& Cho, H.S. (1998). Microsurgical Telerobot System. IEEE/RSJ International Conference on Intelligent Robots and Systems, 1998;94550

Marohn, C.M.R. \& Hanly, C.E.J. (2004). Twenty-first century surgery using twenty-first century technology: surgical robotics. Current Surgery, 2004;61(5):466-73

Maurin, B.; Piccin, O.; Bayle, B.; Gangloff, J.; De Mathelin, M.; Soler, L. \& Gangi, A. (2004). A New Robotic system for CT-guided percutaneous procedures with haptic feedback. International Congress Series, 2004;1268:515-20

Mayer, H.; Nagy, I.; Knoll, A.; Schirmbeck, E.U. \& Bauernschmitt, R. (2004). Robotic system to evaluate force feedback in minimally invasive computer aided surgery. ASME eProceedings of the International Design Engineering Technical Conferences $\mathcal{E}$ Computers and Information in Engineering Conference DETC/CIE, 2004

Mayer, H.; Nagy, I.; Knoll, A.; Schirmbeck, E.U. \& Bauernschmitt R. (2005). An experimental system for robotic heart surgery. Proceedings of the $18^{\text {th }}$ IEEE Symposium on Computer-Based Medical Systems CBMS, 2005

Mitsuishi, M.; Tomisak, S.; Yoshidome, T.; Hashizume, H. \& Fujiwara, K. (2000). Tele-micro surgery system with intelligent user interface. IEEE International Conference on Robotics and Automation ICRA, 2000;2:1607-14

Nagy, I.; Mayer, H.; Knoll, A.; Schirmbeck, E.U. \& Bauernschmitt R. (2004). Real-time matching of angiographies with in situ heart image sequences. IEEE Proceedings of the 17th IEEE Symposium on Computer-Based Medical Systems CBMS, 2004;516-22

Okamura, A.M. (2004). Methods for haptic feedback in teleoperated robot-assisted surgery. Industrial Robot: An International Journal, 2004;31(6):499-508

Schirmbeck, E.U.; Nagy, I.; Mayer, H.; Knoll, A.; Lange, R. \& Bauernschmitt, R. (2004 a). Automatic coronary artery detection on in situ heart images. IEEE Proceedings of the 31st Annual Meeting of Computers in Cardiology CinC, 2004, 85-788, ISBN 0-7803-89271, Chicago/IL, IEEE, Piscataway/NJ

Schirmbeck, E.U.; Nagy, I.; Mayer, H.; Knoll, A.; Lange, R. \& Bauernschmitt, R. (2004 b). Evaluation of force feedback in minimally invasive robotic surgery. Biomed Tech, 2004;49,2:108-9

Schirmbeck, E.U.; Haßelbeck, C.; Mayer, H.; Nagy, I.; Knoll, A.; Freyberger, F.K.B.; Popp, M.M.; Lange. R. \& Bauernschmitt, R. (2005). Evaluation of haptic in robotic heart surgery. Proceedings of the 19th International Congress and Exhibition Computer Assisted Radiology and Surgery CARS, 2005. International Congress Series, Elsevier. 730-734

Suematsu, Y. \& Del Nido, P.J. (2004). Robotic pediatric cardiac surgery: Present and future perspectives. Am J Surg, 2004;188(4A):98S-103S

Thompson, J.; Ottensmeier, M. \& Sheridan, T. (1999). Human factors in telesurgery: effects of time delay and asynchrony in video and control feedback with local manipulative assistance. Telemed Journal, 1999;5(2):129-37 
Van Beers, R.J.; Sittig, A.C. \& Van der Gon, J.J.D. (1999). Integration of proprioceptive and visual position-information: an experimentally supported model. The American Physiological Society, 1999;1355-64

Voges, U.; Holler, E.; Neisius, B.; Schurr, M. \& Vollmer, T. (1997). Evaluation of ARTEMIS, the Advanced Robotics and Telemanipulator System for Minimally Invasive Surgery. Proceedings International Advanced Robotics Programme IARP, 1997;137-48

Wiemeyer, J. (2002). Flimmerverschmelzungsfrequenz und zentralnervöse Aktivierung. Neurol Rehabil, 2002;8(1):29-34 


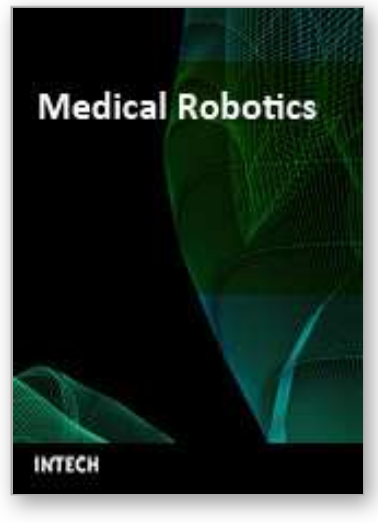

\author{
Medical Robotics \\ Edited by Vanja Bozovic
}

ISBN 978-3-902613-18-9

Hard cover, 526 pages

Publisher I-Tech Education and Publishing

Published online 01, January, 2008

Published in print edition January, 2008

The first generation of surgical robots are already being installed in a number of operating rooms around the world. Robotics is being introduced to medicine because it allows for unprecedented control and precision of surgical instruments in minimally invasive procedures. So far, robots have been used to position an endoscope, perform gallbladder surgery and correct gastroesophogeal reflux and heartburn. The ultimate goal of the robotic surgery field is to design a robot that can be used to perform closed-chest, beating-heart surgery. The use of robotics in surgery will expand over the next decades without any doubt. Minimally Invasive Surgery (MIS) is a revolutionary approach in surgery. In MIS, the operation is performed with instruments and viewing equipment inserted into the body through small incisions created by the surgeon, in contrast to open surgery with large incisions. This minimizes surgical trauma and damage to healthy tissue, resulting in shorter patient recovery time. The aim of this book is to provide an overview of the state-of-art, to present new ideas, original results and practical experiences in this expanding area. Nevertheless, many chapters in the book concern advanced research on this growing area. The book provides critical analysis of clinical trials, assessment of the benefits and risks of the application of these technologies. This book is certainly a small sample of the research activity on Medical Robotics going on around the globe as you read it, but it surely covers a good deal of what has been done in the field recently, and as such it works as a valuable source for researchers interested in the involved subjects, whether they are currently "medical roboticists" or not.

\title{
How to reference
}

In order to correctly reference this scholarly work, feel free to copy and paste the following:

Eva U. Braun, Hermann Mayer, Alois Knoll, Ruediger Lange and Robert Bauernschmitt (2008). The Must-Have in Robotic Heart Surgery: Haptic Feedback, Medical Robotics, Vanja Bozovic (Ed.), ISBN: 978-3-902613-18-9, InTech, Available from: http://www.intechopen.com/books/medical_robotics/the_musthave_in_robotic_heart_surgery_haptic_feedback

\section{INTECH}

open science | open minds

\section{InTech Europe}

University Campus STeP Ri

Slavka Krautzeka 83/A

51000 Rijeka, Croatia

\section{InTech China}

Unit 405, Office Block, Hotel Equatorial Shanghai

No.65, Yan An Road (West), Shanghai, 200040, China

中国上海市延安西路65号上海国际贵都大饭店办公楼405单元 
Phone: +385 (51) 770447

Fax: +385 (51) 686166

www.intechopen.com
Phone: +86-21-62489820

Fax: +86-21-62489821 
(C) 2008 The Author(s). Licensee IntechOpen. This chapter is distributed under the terms of the Creative Commons Attribution-NonCommercialShareAlike-3.0 License, which permits use, distribution and reproduction for non-commercial purposes, provided the original is properly cited and derivative works building on this content are distributed under the same license. 